\title{
Ginger facilitates cell migration and heat tolerance in mouse fibroblast cells
}

\author{
NAOTOSHI SUGIMOTO ${ }^{1-3}$, MASANORI KATAKURA $^{2,4}$, KENTARO MATSUZAKI $^{2}$, MAYUMI MIYAMOTO $^{2}$, \\ ERI SUMIYOSHI $^{2}$, TAIZO WADA ${ }^{3}$, AKIHIRO YACHIE ${ }^{3}$, HIROYUKI NAKAMURA $^{5}$ and OSAMU SHIDO ${ }^{2}$ \\ ${ }^{1}$ Department of Physiology, Graduate School of Medical Sciences, Kanazawa University, Kanazawa, \\ Ishikawa 920-8640; ${ }^{2}$ Department of Environmental Physiology, School of Medicine, Shimane University, Izumo, \\ Shimane 693-8501; ${ }^{3}$ Department of Pediatrics, Graduate School of Medical Sciences, Kanazawa University, Kanazawa, \\ Ishikawa 920-8640; ${ }^{4}$ Department of Nutritional Physiology, Faculty of Pharmaceutical Sciences, Josai University, \\ Sakado, Saitama 350-0295; ${ }^{5}$ Department of Public Health Pediatrics, Graduate School of Medical Sciences, \\ Kanazawa University, Kanazawa, Ishikawa 920-8640, Japan
}

Received July 16, 2020; Accepted December 3, 2020

DOI: $10.3892 / \mathrm{mmr} .2021 .11889$

\begin{abstract}
The components of ginger root (Zingiber officinale Roscoe) are widely used for various medicinal purposes. Several bioactive compounds have been identified in ginger, including 6-, 8- and 10-gingerols, and 6-shogaol, which are agonists of the thermo-sensors transient receptor potential (TRP) cation channel subfamily V member 1 and TRP ankyrin 1. Our previous study demonstrated that ginger powder may affect human metabolism in vivo. However, the effects of the bioactive compounds of ginger on cells have not been completely elucidated. The present study investigated whether ginger powder extracts could modify cell functions in mouse fibroblast cells. The active components of ginger powder extracts were characterized using high-performance liquid chromatography. The activation of protein kinases, actin assembly, cell migration, expression levels of heat shock proteins (HSPs) and cell viability after heat shock were analyzed in NIH3T3 mouse fibroblast cells. Subsequently, 6-, 8-, 10- and 12-gingerols, as well as 6-, 8- and 10-shogaols, were detected in ginger powder extracts. The levels of phosphorylated Akt, mTOR, ERK and p38 MAPK increased after a 10-min stimulation with ginger powder extracts. In addition,
\end{abstract}

Correspondence to: $\mathrm{Dr}$ Naotoshi Sugimoto, Department of Physiology, Graduate School of Medical Sciences, Kanazawa University, 13-1 Takara-machi, Kanazawa, Ishikawa 920-8640, Japan

E-mail: ns@med.kanazawa-u.ac.jp

Dr Kentaro Matsuzaki, Department of Environmental Physiology, School of Medicine, Shimane University, 89-1 En-ya-cho, Izumo, Shimane 693-8501, Japan

E-mail: matuzaki@med.shimane-u.ac.jp

Key words: ginger, gingerol, shogaol, actin assembly, heat shock proteins, heat tolerance
HSP expression levels, lamellipodia formation occurring at cell edges, cell migration and tolerance against heat shock were facilitated following ginger powder extract stimulation. These results suggest that ginger modified cell functions, including actin assembly and heat tolerance, in vitro.

\section{Introduction}

The components of ginger root (Zingiber officinale Roscoe, Zingiberaceae) are widely used for various medicinal purposes all over the world (1). One of the well-known effects of ginger is relief of gastrointestinal symptoms, including hyperemesis gravidarum and nausea (2). Several bioactive compounds - that is, 6-, 8- and 10-gingerols, and 6-shogaol - have been identified in ginger $(3,4)$. These bioactive compounds function as antagonists of cholinergic and serotonergic receptors (5) and, in turn, might induce prevention of hyperemesis gravidarum and nausea (2). Meanwhile, one of the generally acknowledged beneficial effects of ginger consumption is an induction of a 'warm sensation.' Recently, we demonstrated that ginger powder might affect human metabolism in vivo (6). Interestingly, 6-, 8- and 10-gingerols, and 6-shogaol act as regulators of transient receptor potential (TRP) cationic channels, including TRP cation channel subfamily $\mathrm{V}$ member 1 (TRPV1), TRP canonical 5 (TRPC5), and TRP ankyrin 1 (TRPA1) (7-9).

TRP cationic channels are nonselective channels and are activated by chemicals and temperature (heat) $(10,11)$. In particular, TRPV1 functions as a sensor for heat $>42^{\circ} \mathrm{C}$ and a capsaicin receptor causing a burning sensation under stimulation of capsaicin that is the 'hot' ingredient in chili peppers. Recently, we showed that moderate heat $\left(39.5^{\circ} \mathrm{C}\right)$ or capsaicin activates protein kinases, upregulates the expression of heat shock proteins (HSPs), and induces morphological changes in mouse fibroblast cells (12-15). If the components of ginger affect cells in a similar manner as heat or capsaicin by activating TRPV1, it is postulated that these components can regulate protein kinases, HSP expression, and cell morphology. 
However, the effects of such components on cells have not been fully elucidated.

In this study, to determine whether ginger powder extracts (GPE) modify cell functions, we conducted various in vitro experiments in NIH3T3 mouse fibroblast cells. We investigated the effects of GPE on cellular responses; for instance, activation of Akt-mammalian target of rapamycin (mTOR) signaling and mitogen-activated protein kinases (MAPKs), cell morphology and migration, levels of HSPs, and heat tolerance - in mouse fibroblast cells.

\section{Materials and methods}

Chemicals. Dried ginger powder was provided by Sunsho Pharmaceutical Co., Ltd. Dulbecco's modified Eagle's medium (DMEM) was obtained from Wako Pure Chemical Industries, Ltd., whereas fetal bovine serum (FBS) was obtained from Invitrogen; Thermo Fisher Scientific, Inc. Anti-phospho-mTOR (Ser2448) rabbit antibody (\#2971), anti-mTOR rabbit antibody (\#2983), anti-phospho-Akt (Ser473) rabbit antibody (\#9271), anti-Akt rabbit antibody (\#9272), anti-phospho-specific p38 mitogen-activated protein kinase (p38 MAPK) (Thr180/Tyr182) rabbit antibody (\#9211), anti-p38 MAPK rabbit antibody (\#9212), anti-phospho-specific extracellular signal-regulated kinase (ERK1/2) (Thr202/Tyr204) (20G11) rabbit antibody (\#4376), anti-ERK1/2 rabbit antibody (\#9102), anti-heat shock factor 1 (HSF1) rabbit antibody (\#4356), anti-HSP90 (E289) rabbit antibody (\#4875), anti-HSP70 rabbit antibody (\#4872), anti-HSP40 rabbit antibody (\#4868), anti-glyceraldehyde-3-phosphate dehydrogenase (GAPDH) rabbit antibody (\#2118), and horseradish peroxidase (HRP)-conjugated anti-rabbit IgG (\#7074) were purchased from Cell Signaling Technology, Inc.. Meanwhile, EzWestBlue was purchased from ATTO Corp.

Preparation and characterization of GPE. GPE was extracted from dried ginger powder (Sunsho Pharmaceutical Co., Ltd. Shizuoka, Japan) with $95 \%$ ethanol and dry down with $\mathrm{N}_{2}$ gas. Then, residues were dissolved in dimethyl sulfoxide (DMSO). The active components of GPE used in this study were characterized using high-performance liquid chromatography (HPLC). The active components of GPE were measured as described by Yu et al (4) and Tao et al (3) with a slight modification. Briefly, HPLC was combined with electrospray ionization/tandem mass spectrometry (LC-ESI-MS/MS) in a TSQ Quantum mass spectrometer (Thermo Fisher Scientific, Inc.). HPLC was conducted in a Luna $3 \mathrm{u} \mathrm{C18} \mathrm{(2)} 100$ Å LC column $(100 \times 2.0 \mathrm{~mm}$; Phenomenex) at $30^{\circ} \mathrm{C}$. Samples were eluted with a mobile phase composed of acetonitrile-methanol $(4: 1, \mathrm{v} / \mathrm{v})$ and water-acetic acid $(100: 0.1, \mathrm{v} / \mathrm{v})$ in a 20:80 ratio for $5 \mathrm{~min}$, then ramped up to a 100:0 ratio after $10 \mathrm{~min}$, and held for $5 \mathrm{~min}$ at a flow rate of $0.2 \mathrm{ml} / \mathrm{min}$. MS/MS analyses were conducted in positive ion mode, and 6-, 8-, 10- and 12-gingerols and 6-, 8- and 10-shogaols were detected and quantified with selected reaction monitoring. Peaks were selected, and their areas were calculated using Xcalibur 2.1 software (TThermo Fisher Scientific, Inc.). The main active components in GPE are summarized in Table I.

For treatment of cells, GPE stock solutions dissolved in DMSO at the concentrations of $0.001,0.01,0.1$, and $1.0 \mathrm{mg} / \mathrm{ml}$ were prepared and stored at $-20^{\circ} \mathrm{C}$ until use. The respective
GPE stock solutions were diluted 1:1,000 (v/v) in the cell culture medium. Resultantly, the final concentration of GPE in culture medium used in each experiment was $0.001,0.01,0.1$, and $1.0 \mathrm{mg} / \mathrm{ml}$, respectively.

Cell culture. NIH3T3 mouse fibroblast cells were provided by Dr Nobuhiko Komine (Kanazawa University). The cells were maintained in DMEM containing $10 \% \mathrm{FBS}$ at $37^{\circ} \mathrm{C}$ in a $5 \% \mathrm{CO}_{2}$ incubator.

Western blotting. Western blotting was performed as described previously (16). Briefly, proteins were extracted from cells, and protein concentrations were determined using Pierce BCA protein assay kit (Thermo Fisher Scientific, Inc.) according to the manufactures protocol. Equal amounts of protein $(30 \mu \mathrm{g})$ were separated from each sample using $10 \%$ sodium dodecyl sulfate-polyacrylamide gel electrophoresis (SDS-PAGE). The resolved proteins were transferred onto polyvinylidene fluoride (PVDF) membranes, which were incubated with primary antibodies (1:1,000), followed by incubation with HRP-linked secondary antibodies $(1: 2,000)$.

Actin filament staining. To evaluate the actin cytoskeletons, cells were fixed in $3.7 \%(\mathrm{v} / \mathrm{v})$ formaldehyde in Dulbecco's phosphate-buffered saline (PBS) and processed as described previously (17). F-actin was visualized with tetramethylrhodamine (TRITC)-labeled phalloidin under an inverted EVOS fluorescence microscope (Life Technologies Japan).

Cell viability assay. Cell viability was analyzed using the Cell Counting Kit-8 (Wako Pure Chemical Industries, Ltd.) as described previously (16). NIH3T3 cells were seeded in 96-well plates at a density of $1 \times 10^{3}$ cells/well. After $24 \mathrm{~h}$ of incubation, the cells were treated with $0.001-1.0 \mu \mathrm{g} / \mathrm{ml}$ of GPE for 2 days. Next, the cells were incubated with $10 \mu \mathrm{l} \mathrm{CCK}-8$ for $3 \mathrm{~h}$ at $37^{\circ} \mathrm{C}$. The absorbance of the colored formazan product produced by mitochondrial dehydrogenases in metabolically active cells was recorded at $450 \mathrm{~nm}$. Cell viability was expressed as a ratio of the absorbance obtained in treated wells relative to that in untreated (control: $0.1 \%$ DMSO) wells.

Wound healing assay (cell migration). A wound healing assay was performed to evaluate the migration ability of the cells. Cells were passaged into $35-\mathrm{mm}$ dishes. When the cells reached to the $90 \%$ confluence, an injury line of $2 \mathrm{~mm}$ width was drawn using a pipet tip. The dishes were rinsed with PBS and incubated with DMEM. The images were obtained after $16 \mathrm{~h}$ of incubation and the wound closure was measured.

Severe heat shock treatment. The cells were exposed to $45^{\circ} \mathrm{C}$ temperature for $30 \mathrm{~min}$ after a 2-day treatment with or without $\mathrm{GPE}$ at $37^{\circ} \mathrm{C}$ in $5 \% \mathrm{CO}_{2}$. One day after the heat shock treatment, cell viability was analyzed using the Cell Counting Kit- 8 as described above.

Statistical analysis. Data are presented as the mean \pm standard error of the mean (SEM) from at least three independent experiments. Statistical analysis was performed using a 
Table I. Main bioactive components in ginger powder extracts $(100 \mu \mathrm{g})$ used in the present study.

\begin{tabular}{lc}
\hline Bioactive components & Weight, $\mu \mathrm{g}$ \\
\hline 6-Gingerol & 23.68 \\
8-Gingerol & 3.80 \\
10-Gingerol & 5.22 \\
12-Gingerol & 0.15 \\
6-Shogaol & 51.38 \\
8-Shogaol & 7.18 \\
10-Shogaol & 4.58 \\
\hline
\end{tabular}

Student's unpaired t-test or a Kruskal-Wallis nonparametric analysis of variance (ANOVA) with Dunn's post hoc test, and results were considered statistically significant when $\mathrm{P}<0.05$ or $\mathrm{P}<0.01$.

\section{Results}

Low doses of GPE do not affect cell viability in mouse fibroblast cells. Several previous reports have shown that the ingredients of GPE, gingerol and shogaol have toxic effects on the cells (18-20). However, in this study, we found that low doses of GPE $(0.001-0.1 \mu \mathrm{g} / \mathrm{ml})$ had a minimal effect on cell viability. As shown in Fig. 1, the low doses (0.001-0.1 $\mu \mathrm{g} / \mathrm{ml})$ of GPE did not significantly decrease the cell viability. Therefore, we used 0.001-0.1 $\mu \mathrm{g} / \mathrm{ml}$ doses of GPE for the subsequent experiments.

GPE activate Akt/mTOR signaling. To determine whether GPE activates Akt/mTOR signaling pathway, we detected phosphorylated Akt (phospho-Akt) and phosphorylated mTOR (phospho-mTOR) by western blot. Western blot analysis revealed that the GPE increased phospho-Akt and phospho-mTOR levels in NIH3T3 cells (Fig. 2). These results indicate that the GPE activates Akt/mTOR signaling pathway. These result indicate that the activation of Akt-mTOR signaling and increase in intracellular phosphatidylinositol 3-phosphate (PtdIns3P or PI3P). PI3P stimulates Rho family small $\mathrm{G}$ proteins (Rho, Rac, and $\mathrm{Cdc} 42$ ) as well as Akt (17,21), and, in turn, regulates cell morphology and cell migration.

GPE regulate cell morphology and stimulate cell migration. Microscopic examination indicated that GPE changed cell morphology and promoted cell migration (Fig. 3). We observed that lamellipodia formation occurred at the cell edges (Fig. 3, upper), which is known to facilitate cell migration (22). In fact, a 16-h treatment with GPE narrowed the wound area in vitro (Fig. 3, lower), indicating acceleration of cell migration.

GPE activate ERK and $p 38$ MAPK in mouse fibroblast cells. MAPKs, including ERK and p38 MAPK, play crucial roles in the transduction from extracellular stimuli to intracellular signaling $(15,22)$. Next, we tested the effects of GPE on ERK and p38 MAPK in the cells. A 10-min treatment with GPE

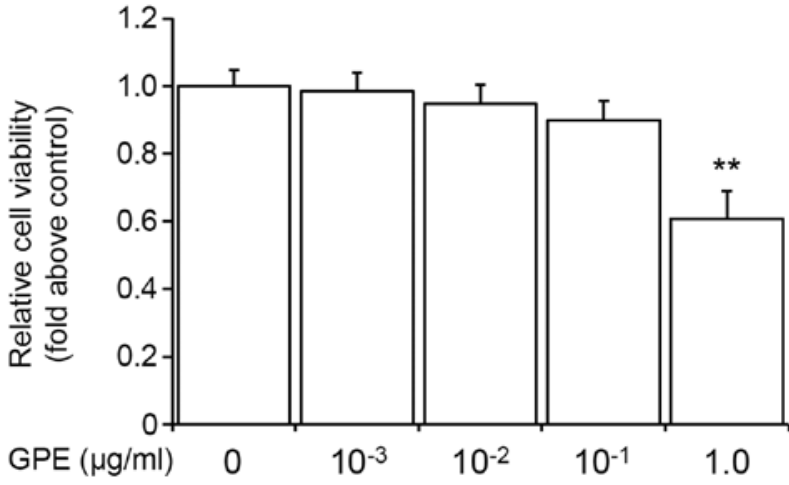

Figure 1. Changes in cell viability in mouse fibroblast cells following treatment with GPE. The cells were stimulated with GPE $(0.001-1.0 \mu \mathrm{g} / \mathrm{ml})$ for 2 days. Cell viability was analyzed using a Cell Counting Kit-8. Data are presented as the mean \pm SEM $(n=12)$. Statistical analysis was conducted using a Kruskal-Wallis test followed by Dunn's post hoc test. ${ }^{* *} \mathrm{P}<0.01$ vs GPE-untreated control. GPE, ginger powder extracts.
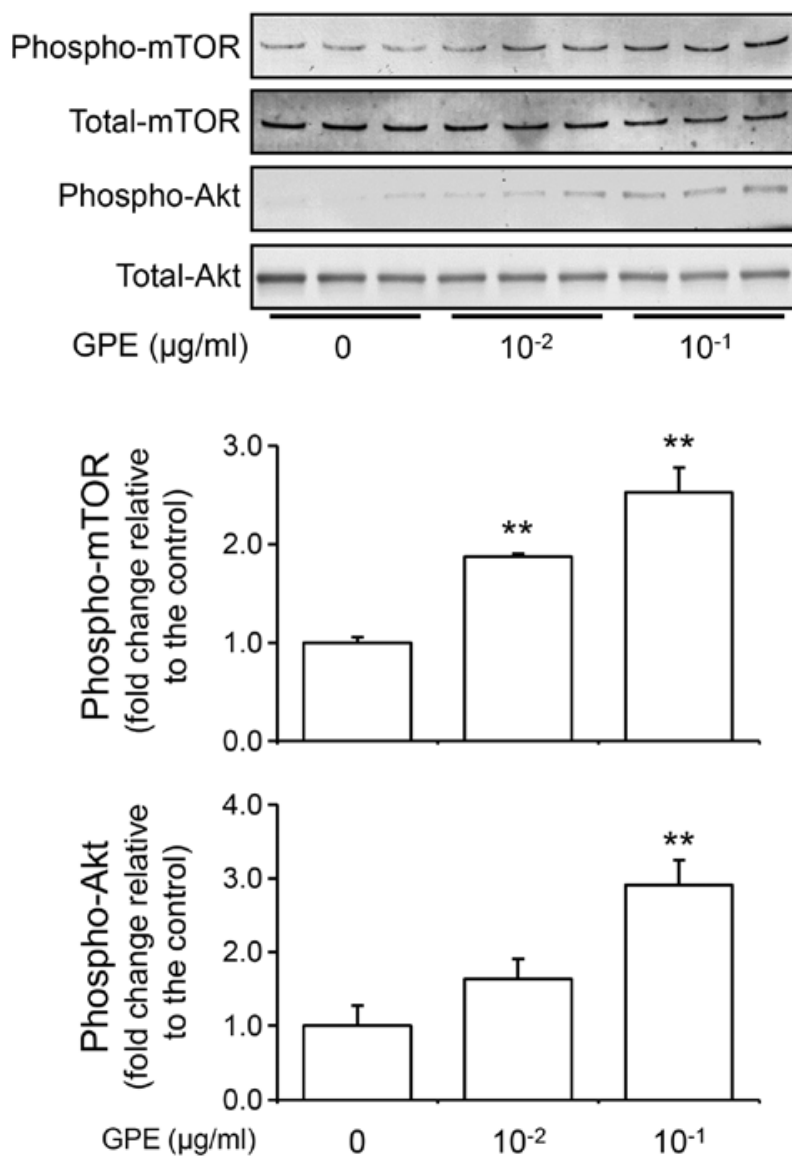

Figure 2. GPE phosphorylate Akt and mTOR in mouse fibroblast cells. Effect of GPE on Akt and mTOR phosphorylation. The cells were stimulated with GPE $(0.01$ and $0.1 \mu \mathrm{g} / \mathrm{ml})$ for $10 \mathrm{~min}$. Total cell extracts were analyzed for Akt and mTOR phosphorylation using western blotting. The densities of bands corresponding to phosphorylated Akt, phosphorylated mTOR, total Akt and total mTOR were semi-quantified by densitometry. Data are presented as the mean \pm SEM of three independent experiments. Statistical analysis was conducted using a Kruskal-Wallis test followed by Dunn's post hoc test. ${ }^{* *} \mathrm{P}<0.01$ vs. untreated controls. GPE, ginger powder extracts.

increased the phosphorylation of ERK and p38 MAPK in a dose-dependent manner (Fig. 4), indicating that the GPE activates ERK and p38 MAPK. 


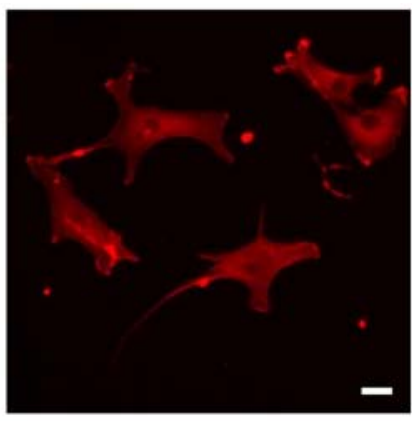

GPE $(\mu \mathrm{g} / \mathrm{ml})$
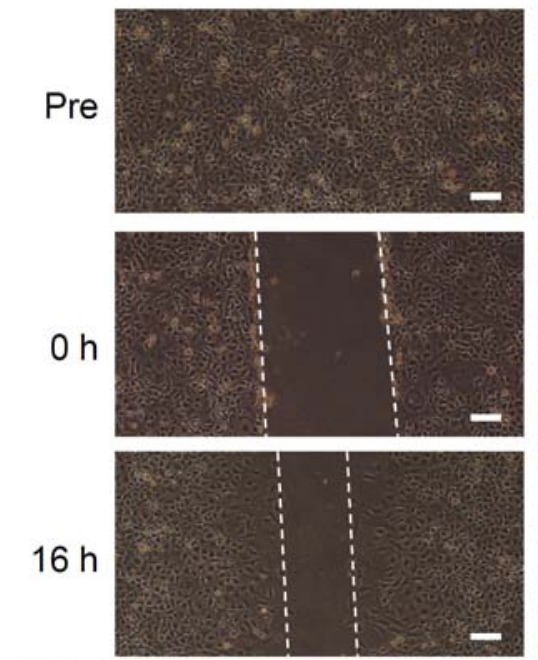

$\operatorname{GPE}(\mu \mathrm{g} / \mathrm{ml})$

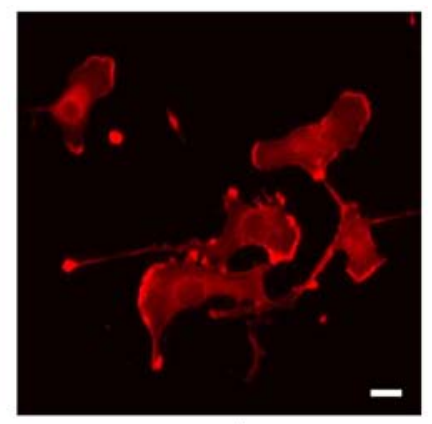

$10^{-1}$
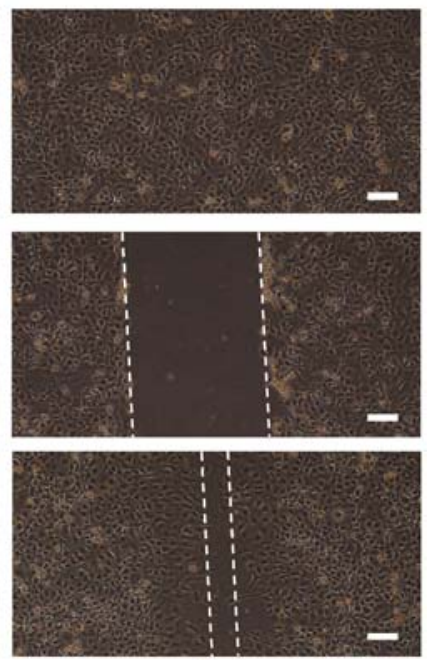

$10^{-1}$

Figure 3. GPE modify actin assembly and facilitate cell migration in mouse fibroblast cells. (Top) Effect of GPE on actin assembly. The cells were treated with GPE $(0.1 \mu \mathrm{g} / \mathrm{ml})$ for $15 \mathrm{~min}$ and stained with tetramethylrhodamine-phalloidin for visualization of F-actin. Results are representative of three independent experiments. Scale bar, $20 \mu \mathrm{m}$. (Bottom) Effect of GPE on cell migration. The figures show cells before (Pre), immediately after $(0 \mathrm{~h})$ and $16 \mathrm{~h}$ after the wound was created $(16 \mathrm{~h})$. The cells were treated with GPE $(0.1 \mu \mathrm{g} / \mathrm{ml})$ or vehicle for $16 \mathrm{~h}$ after the wound was created. Results are representative of three independent experiments. GPE, ginger powder extracts. Scale bar, $200 \mu \mathrm{m}$.
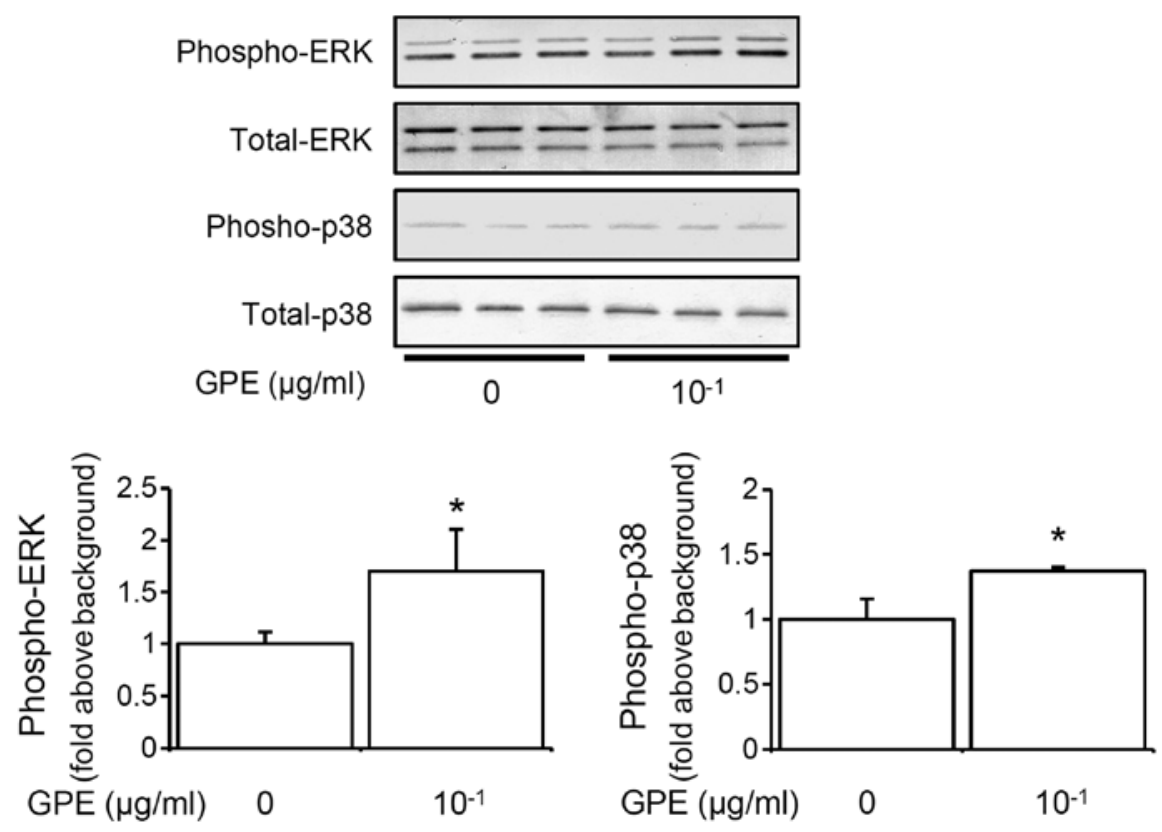

Figure 4. GPE phosphorylate ERK and p38 MAPK in mouse fibroblast cells. Effect of GPE on ERK and p38 MAPK phosphorylation. The cells were stimulated with GPE $(0.1 \mu \mathrm{g} / \mathrm{ml})$ for $10 \mathrm{~min}$. Total cell extracts were analyzed for ERK or p38 MAPK phosphorylation using western blotting. The densities of bands corresponding to phosphorylated ERK, phosphorylated p38 MAPK, total ERK and total p38 were semi-quantified by densitometry. Data are presented as the mean \pm SEM of three independent experiments. Statistical analysis was conducted using a Kruskal-Wallis test followed by Dunn's post hoc test. "P $<0.05$ vs. untreated controls. GPE, ginger powder extracts. 

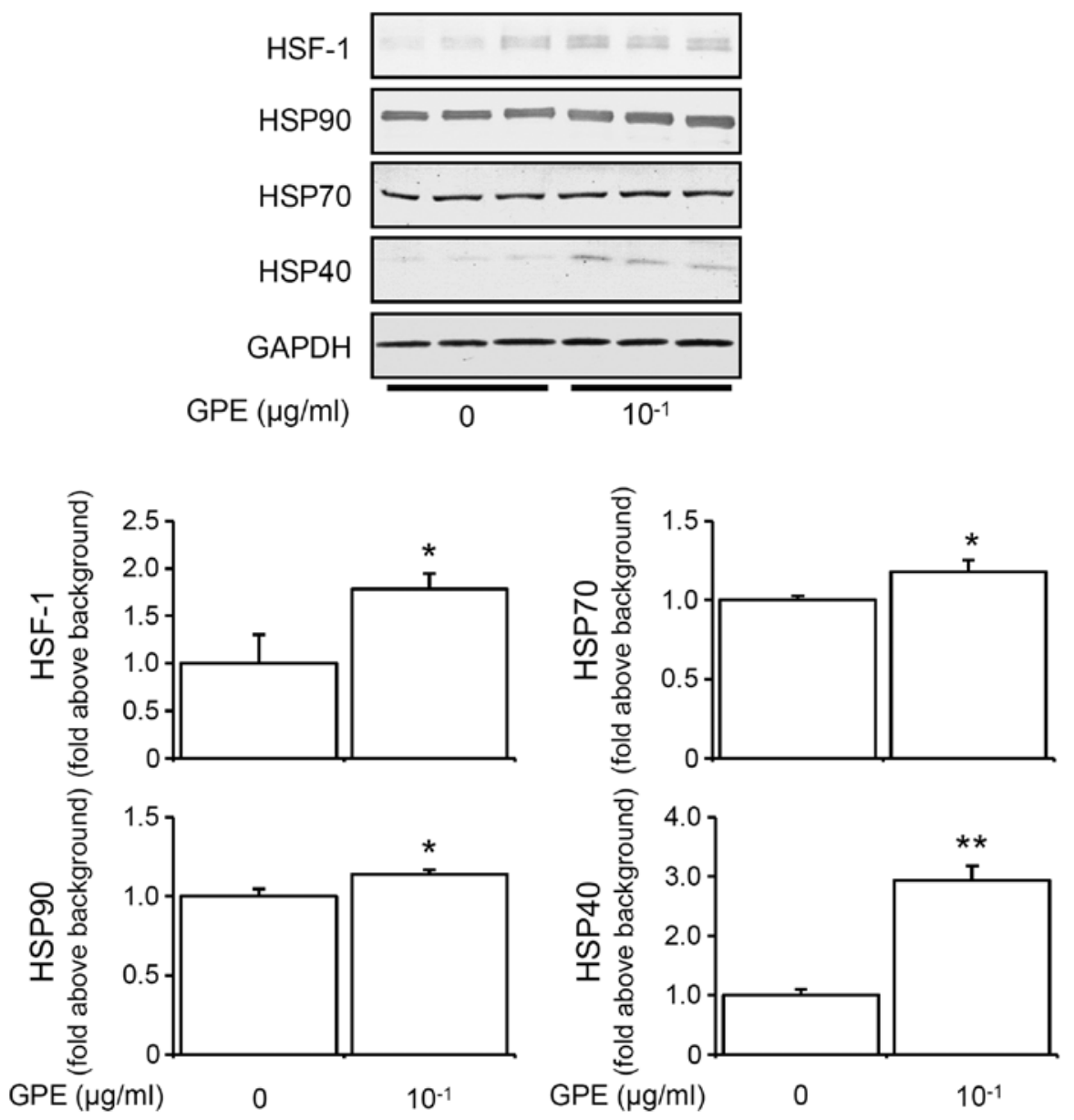

Figure 5. GPE induce HSF-1 and HSP expression in mouse fibroblast cells. Effect of GPE on protein expression levels of HSF-1, HSP90, HSP70 and HSP40. The cells were stimulated with GPE $(0.1 \mu \mathrm{g} / \mathrm{ml})$ for 2 days. Total cell extracts were analyzed for HSF-1, HSP90, HSP70 and HSP40 expression using western blotting. The densities of bands corresponding to HSF-1, HSP90, HSP70 and HSP40 were semi-quantified by densitometry. Data are presented as the mean \pm SEM of three independent experiments. Statistical analysis was conducted using Student's unpaired t-test. ${ }^{~} \mathrm{P}<0.05$ and ${ }^{* *} \mathrm{P}<0.01$ vs. GPE-untreated controls. GPE, ginger powder extracts; HSF-1, heat shock factor-1; HSP, heat shock protein.

GPE induces HSF1, HSP90, HSP70 and HSP40 expression. Continuous exposure to heat induces the upregulation of HSPs in vitro $(23,24)$. Previously, we had also shown that continuous 2-day exposure to moderate heat increased HSP70 and HSP90 expressions (12). We therefore speculated whether GPE upregulates HSPs expressions in mouse fibroblast cells. Interestingly, the expression of HSF1, HSP90, HSP70, and HSP40 was increased after a 2-day continuous treatment with GPE in NIH3T3 cells (Fig. 5). These results indicated that ginger might induce upregulation of HSPs similar to the effect of heat exposure.

GPE attenuates severe heat shock-induced cell death. HSPs play an important role in protecting cells from environmental stressors such as heat shock $(14,15,23,24)$. Thus, we examined whether a continuous 2-day treatment with GPE can improve heat tolerance by measuring cell viability after severe heat shock in mouse fibroblast cells. The cells were incubated at $45^{\circ} \mathrm{C}$ for $30 \mathrm{~min}$ (severe heat shock) after an initial 2-day treatment with GPE at $37^{\circ} \mathrm{C}$. Cell viability was determined after 1 day of severe heat shock.

Results showed that although severe heat shock decreased cell viability, GPE treatment was able to attenuate heat

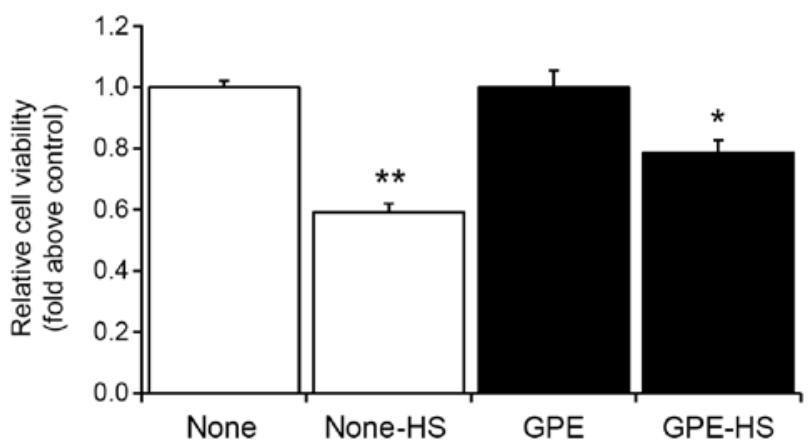

Figure 6. Change in cell viability 1 day after HS following a 2-day treatment with GPE of mouse fibroblast cells. The cells were stimulated with $\operatorname{GPE}(0.1 \mu \mathrm{g} / \mathrm{ml})$ for 2 days. The cells were incubated at $45^{\circ} \mathrm{C}$ for $30 \mathrm{~min}$ (severe HS) and were then returned to incubation at $37^{\circ} \mathrm{C}$. Cell proliferation was analyzed 1 day after severe $\mathrm{HS}$, and cell viability was examined using a Cell Counting Kit- 8 assay. Data are presented as the mean \pm SEM $(n=8)$. Statistical analysis was conducted using a Kruskal-Wallis test followed by Dunn's post hoc test. ${ }^{*} \mathrm{P}<0.05$ and ${ }^{* *} \mathrm{P}<0.01$ vs. each control. GPE, ginger powder extracts; HS, heat shock.

shock-induced cell death in mouse fibroblast cells (Fig. 6). This result suggested that GPE may facilitate heat tolerance in vitro. 


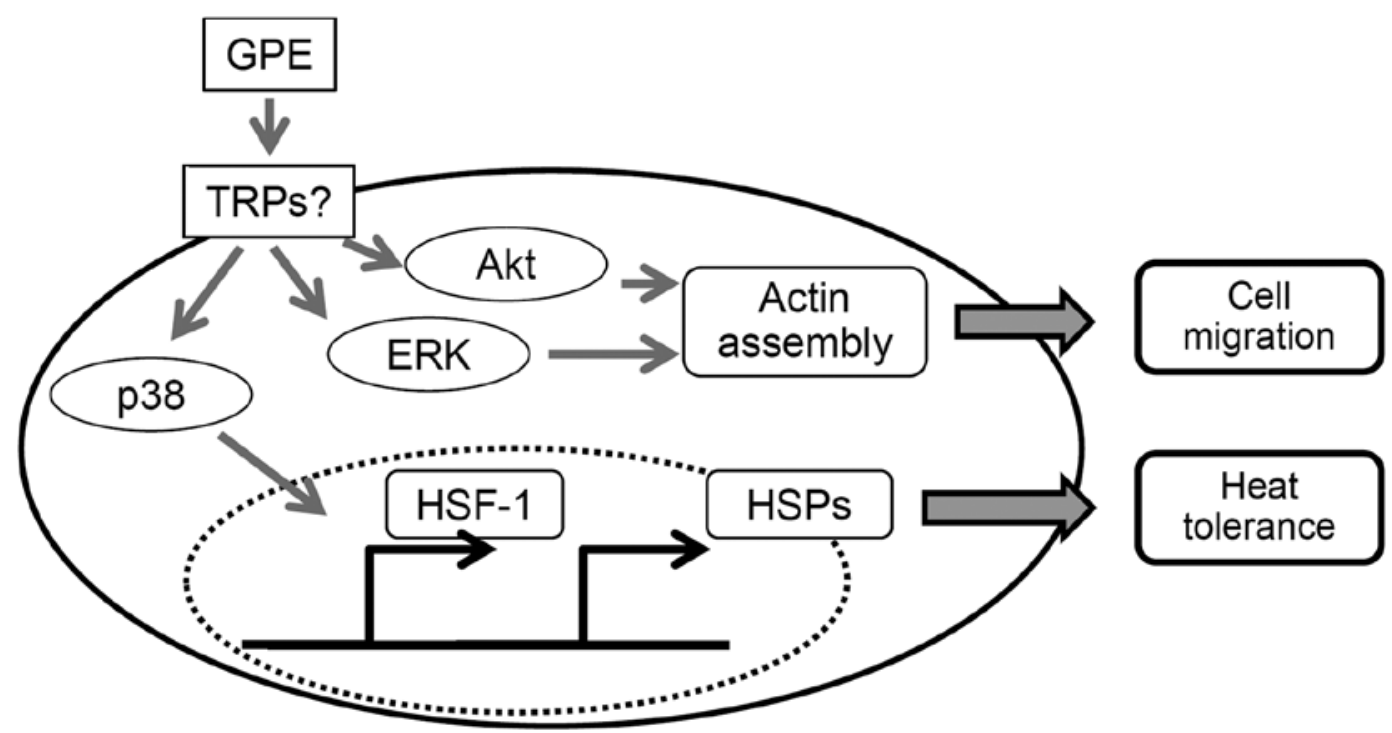

Figure 7. Schematic diagram showing how GPE facilitate cell migration and heat tolerance in mouse fibroblast cells. GPE activate protein kinases, including Akt, ERK and p38 MAPK. Akt and ERK accelerate cell migration though actin assembly. p38 MAPK increases the expression levels of HSPs through HSF-1 activation and, in turn, facilitates heat tolerance. GPE, ginger powder extracts; TRPs, transient receptor potential cationic channels; ERK, extracellular signal-regulated kinase; MAPK, mitogen-activated protein kinase; HSF-1, heat shock factor-1; HSP, heat shock protein.

\section{Discussion}

Several bioactive compounds-6-, 8-, 10-, and 12-gingerols and 6-, 8- and 10-shogaols-were identified in GPE (Table I). However, the effects of these bioactive compounds on cells have not been fully elucidated in vitro. The results of our investigation provide evidence that GPE activated phosphoinositide 3-kinase (PI3K)-Akt-mTOR and MAPKs, facilitated cell migration and expression levels of HSPs, and attenuated heat shock-induced cell death in mouse fibroblast cells.

Treatment with GPE $(\sim 0.1 \mu \mathrm{g} / \mathrm{ml})$ did not affect cell viability, indicating that GPE $(\sim 0.1 \mu \mathrm{g} / \mathrm{ml})$ is nontoxic to mouse fibroblast cells, in contrast to several reports showing that the ingredients of ginger extracts, such as gingerol and shogaol, have cytotoxic activity (18-20). The discrepancy in the findings regarding the cytotoxic activity of ginger might be attributable to the difference in the doses of GPE used. In our study, the dose used was $\sim 0.1 \mu \mathrm{g} / \mathrm{ml}$, whereas Akimoto et al (18) used $\sim 25 \mu \mathrm{g} / \mathrm{ml}$. Interestingly, the total levels of free 6-, 8- and 10-gingerols and 6-shogaol in serum $60 \mathrm{~min}$ after the oral intake of GPE in humans were $<0.1 \mu \mathrm{g} / \mathrm{ml}(25)$. Therefore, the physiological response to lower doses of ginger constituents-rather than higher doses-is likely to be of greater importance. The doses of GPE $(0.01-0.1 \mu \mathrm{g} / \mathrm{ml})$ used in our study were appropriate for elucidating the effect of ginger on cells.

Actin assembly and cell migration are regulated by the activity of a number of signaling molecules $(15,22)$. Lamellipodia are formed by actin assembly at the edge of a cell in the direction of migration. PI3K activation is known to phosphorylate Akt (Akt activation) and induce lamellipodia formation $(15,22)$. After Akt activation by PI3K, Akt phosphorylates mTOR $(15,22,26)$. Here, we have shown that GPE phosphorylate Akt and mTOR in mouse fibroblast cells, indicating that they activate the PI3K-Akt-mTOR pathway. Moreover, GPE facilitate lamellipodia formation occurring at cell edges and narrow wound areas, indicating acceleration of cell migration. These results suggested that ginger might play a valuable role in wound healing, erosion, or ulcer. In fact, a recent study showed that the Japanese herbal medicine Hangeshashinto, which contains ginger, enhances oral keratinocyte migration to facilitate healing of oral ulcerative mucositis (6). The components contained in ginger may regulate actin assembly and cell migration via the Akt-mTOR pathway. However, there are many other signal cascades that control cytoskeletal polymerization and cell migration other than Akt-mTOR pathway, e.g., Rho-A/Rho-kinase signaling pathway $(27,28)$. The impact of GPE on actin assembly- and cell migration-related signal cascades other than Akt-mTOR pathway should be investigated in the future.

In general, the activation of Akt pathway is related not only to migration but also to proliferation of various types of cells, such as mononuclear macrophages and epithelial cells $(29,30)$. Also, we have previously shown that direct exposure to mild heat increases neural stem/progenitor cells (NSC/NPCs) proliferation concomitant with the upregulation of Akt phosphorylation (31). Since GPE may affect various types of cell proliferation via activation of Akt pathway, the effects of GPE on cell proliferation e.g., mononuclear macrophages, epithelial cells and NSC/NPCs, should be investigated as a continuation of this study.

GPE activated ERK and p38 MAPK. ERK signaling is a crucial regulator of growth, differentiation, and migration (32), whereas p38 MAPK is generally known as the principal stress-activated protein kinase, and the p38 MAPK pathway regulates HSP transcription (33) through the activation of HSF-1 (34). In this study, GPE increased the levels of HSF-1, and HSPs (HSP90, HSP70, and HSP40), concomitant with activation of p38 MAPK.

HSPs play an essential chaperoning role that helps cells maintain cellular protein homeostasis and prevent apoptosis 
under diverse forms of stress (24,35-37). Previously, the upregulation of HSP70 and HSP90 has been shown to cause the development of heat tolerance in mouse fibroblast cells $(12,14,15)$. In this study, GPE attenuated heat shock-induced cell death. These data indicate that ginger may facilitate heat tolerance similar to the effect of heat exposure.

However, our data did not show which receptor mediated ginger-induced cell functions. The bioactive compounds in ginger have been reported to function as antagonists of cholinergic and serotonergic receptors (5) or activators of TRPV1, TRPVC5, and TRPA1 (7-9). Interestingly, TRPV1 and TRPA1 act as thermo-sensors. In this study, we showed that GPE upregulate HSP levels in a similar manner to heat in mouse fibroblast cells. These lines of evidence indicate that ginger might moderate cell functions through TRPs, including TRPV1 and TRPA1 (Fig. 7).

In this study, we showed that GPE accelerate cell migration and prevent heat shock-induced cell death in vitro. These results suggest that ginger might play a valuable role in wound and ulcer healing, preventing erosion, as well as resisting heat shock.

\section{Acknowledgements}

Not applicable.

\section{Funding}

This study was supported by Grants-in-Aid for Science and Culture (grant nos. 25282021, 26650173, 15KT0003, 16K13013 and 17H01963) from the Ministry of Education, Culture, Sports, Science, and Technology of Japan.

\section{Availability of data and materials}

The datasets used and/or analyzed during the current study are available from the corresponding author on reasonable request.

\section{Authors' contributions}

NS designed the study and prepared the manuscript. NS, MK, KM and ES conducted the experiments. MM, TW and HN analyzed the data. NS, MK and KM assessed the authenticity of the data. NS obtained funding. AY and OS contributed to interpretation of data and supervised the study. NS, MK, $\mathrm{KM}, \mathrm{AY}$ and OS revised the manuscript. All authors read and approved the final manuscript.

\section{Ethics approval and consent to participate}

Not applicable.

\section{Patient consent for publication}

Not applicable.

\section{Competing interests}

The authors declare that they have no competing interests.

\section{References}

1. Ali BH, Blunden G, Tanira MO and Nemmar A: Some phytochemical, pharmacological and toxicological properties of ginger (Zingiber officinale Roscoe): A review of recent research. Food Chem Toxicol 46: 409-420, 2008.

2. McParlinC,O'Donnell A, Robson SC,BeyerF,Moloney E, Bryant A, Bradley J, Muirhead CR, Nelson-Piercy C, Newbury-Birch D, et al: Treatments for hyperemesis gravidarum and nausea and vomiting in pregnancy: A systematic review. JAMA 316: 1392-1401, 2016.

3. Tao Y, Li W, Liang W and Van Breemen RB: Identification and quantification of gingerols and related compounds in ginger dietary supplements using high-performance liquid chromatography-tandem mass spectrometry. J Agric Food Chem 57: 10014-10021, 2009.

4. Yu Y, Zick S, Li X, Zou P, Wright B and Sun D: Examination of the pharmacokinetics of active ingredients of ginger in humans. AAPS J 13: 417-426, 2011.

5. Pertz HH, Lehmann J, Roth-Ehrang R and Elz S: Effects of ginger constituents on the gastrointestinal tract: Role of cholinergic M3 and serotonergic 5-HT3 and 5-HT4 receptors. Planta Med 77: 973-978, 2011.

6. Miyano K, Eto M, Hitomi S, Matsumoto T, Hasegawa S, Hirano A, Nagabuchi K, Asai N, Uzu M, Nonaka M, et al: The Japanese herbal medicine Hangeshashinto enhances oral keratinocyte migration to facilitate healing of chemotherapy-induced oral ulcerative mucositis. Sci Rep 10: 625, 2020.

7. Dedov VN, Tran VH, Duke CC, Connor M, Christie MJ, Mandadi S and Roufogalis BD: Gingerols: A novel class of vanilloid receptor (VR1) agonists. Br J Pharmacol 137: 793-798, 2002.

8. Kim YS, Hong CS, Lee SW, Nam JH and Kim BJ: Effects of ginger and its pungent constituents on transient receptor potential channels. Int J Mol Med 38: 1905-1914, 2016.

9. Yin Y, Dong Y, Vu S, Yang F, Yarov-Yarovoy V, Tian Y and Zheng J: Structural mechanisms underlying activation of TRPV1 channels by pungent compounds in gingers. Br J Pharmacol 176: 3364-3377, 2019 .

10. Bandell M, Macpherson LJ and Patapoutian A: From chills to chilis: Mechanisms for thermosensation and chemesthesis via thermoTRPs. Curr Opin Neurobiol 17: 490-497, 2007.

11. Venkatachalam K and Montell C: TRP channels. Annu Rev Biochem 76: 387-417, 2007.

12. Sugimoto N, Katakura M, Matsuzaki K, Nakamura H, Yachie A and Shido O: Capsaicin partially mimics heat in mouse fibroblast cells in vitro. Naunyn Schmiedebergs Arch Pharmacol 390: 281-289, 2017.

13. Sugimoto N, Matsuzaki K, Katakura M, Nakamura H, Ueda Y, Yachie A and Shido O: Heat attenuates sensitivity of mammalian cells to capsaicin. J Biochem Mol Toxicol 33: e22288, 2019.

14. Sugimoto N, Shido O, Matsuzaki K, Katakura M, Hitomi Y, Tanaka M, Sawaki T, Fujita Y, Kawanami T, Masaki Y, et al: Long-term heat exposure prevents hypoxia-induced apoptosis in mouse fibroblast cells. Cell Biochem Biophys 70: 301-307, 2014.

15. Sugimoto N, Shido O, Matsuzaki K, Ohno-Shosaku T, Hitomi Y, Tanaka M, Sawaki T, Fujita Y, Kawanami T, Masaki Y, et al: Cellular heat acclimation regulates cell growth, cell morphology, mitogen-activated protein kinase activation, and expression of aquaporins in mouse fibroblast cells. Cell Physiol Biochem 30: 450-457, 2012.

16. Leu H, Sugimoto N, Shimizu M, Toma T, Wada T, Ohta K and Yachie A: Tumor necrosis factor- $\alpha$ modifies the effects of Shiga toxin on glial cells. Int Immunopharmacol 38: 139-143, 2016.

17. Sugimoto N, Takuwa N, Yoshioka K and Takuwa $Y$ : Rho-dependent, Rho kinase-independent inhibitory regulation of Rac and cell migration by LPA1 receptor in Gi-inactivated CHO cells. Exp Cell Res 312: 1899-1908, 2006.

18. Akimoto M, Iizuka M, Kanematsu R, Yoshida M and Takenaga K: Anticancer effect of ginger extract against pancreatic cancer cells mainly through reactive oxygen species-mediated autotic cell death. PLoS One 10: e0126605, 2015.

19. Kotowski U, Kadletz L, Schneider S, Foki E, Schmid R, Seemann R, Thurnher D and Heiduschka G: 6-shogaol induces apoptosis and enhances radiosensitivity in head and neck squamous cell carcinoma cell lines. Phytother Res 32: 340-347, 2018.

20. Yao C, Oh JH, Oh IG, Park CH and Chung JH: [6]-Shogaol inhibits melanogenesis in B16 mouse melanoma cells through activation of the ERK pathway. Acta Pharmacol Sin 34: 289-294, 2013. 
21. Ueda Y, Ii T, Aono Y, Sugimoto N, Shinji S, Yoshida H and Sato M: Membrane dynamics induced by a phosphatidylinositol 3,4,5-trisphosphate optogenetic tool. Anal Sci 35: 57-63, 2019.

22. Le Clainche $\mathrm{C}$ and Carlier MF: Regulation of actin assembly associated with protrusion and adhesion in cell migration. Physiol Rev 88: 489-513, 2008.

23. Matozaki M, Saito Y, Yasutake R, Munira S, Kaibori Y, Yukawa A, Tada M and Nakayama Y: Involvement of Stat3 phosphorylation in mild heat shock-induced thermotolerance. Exp Cell Res 377: 67-74, 2019.

24. Morotomi T, Kitamura C, Okinaga T, Nishihara T, Sakagami R and Anan H: Continuous fever-range heat stress induces thermotolerance in odontoblast-lineage cells. Arch Oral Biol 59: 741-748, 2014.

25. Miyamoto M, Matsuzaki K, Katakura M, Hara T, Tanabe Y and Shido O: Oral intake of encapsulated dried ginger root powder hardly affects human thermoregulatory function, but appears to facilitate fat utilization. Int J Biometeorol 59: 1461-1474, 2015.

26. Sugimoto N, Katakura M, Matsuzaki K, Sumiyoshi E, Yachie A and Shido O: Chronic administration of theobromine inhibits mTOR signal in rats. Basic Clin Pharmacol Toxicol 124: 575-581, 2019.

27. Qi Y, Liang X, Dai F, Guan H, Sun J and Yao W: RhoA/ROCK pathway activation is regulated by AT1 receptor and participates in smooth muscle migration and dedifferentiation via promoting actin cytoskeleton polymerization. Int J Mol Sci 21: 5398, 2020.

28. Katoh $\mathrm{M}$ and Katoh M: Molecular genetics and targeted therapy of WNT-related human diseases (Review). Int J Mol Med 40 587-606, 2017.

29. Manning BD and Toker A: AKT/PKB signaling: Navigating the network. Cell 169: 381-405, 2017.

30. Shi X, Wang J, Lei Y, Cong C, Tan D and Zhou X: Research progress on the PI3K/AKT signaling pathway in gynecological cancer (Review). Mol Med Rep 19: 4529-4535, 2019.
31. Hossain ME, Matsuzaki K, Katakura M, Sugimoto N, Mamun AA, Islam R, Hashimoto M and Shido O: Direct exposure to mild heat promotes proliferation and neuronal differentiation of neural stem/progenitor cells in vitro. PLoS One 12: e0190356, 2017.

32. Sun Y, Liu WZ, Liu T, Feng X, Yang N and Zhou HF: Signaling pathway of MAPK/ERK in cell proliferation, differentiation, migration, senescence and apoptosis. J Recept Signal Transduct Res 35: 600-604, 2015.

33. Gong X, Luo T, Deng P, Liu Z, Xiu J, Shi H and Jiang Y: Stress-induced interaction between p38 MAPK and HSP70. Biochem Biophys Res Commun 425: 357-362, 2012.

34. Westerheide SD, Raynes R, Powell C, Xue B and Uversky VN: HSF transcription factor family, heat shock response, and protein intrinsic disorder. Curr Protein Pept Sci 13: 86-103, 2012.

35. Sugimoto N, Matsuzaki K, Ishibashi H, Tanaka M, Sawaki T, Fujita Y, Kawanami T, Masaki Y, Okazaki T, Sekine J, et al: Upregulation of aquaporin expression in the salivary glands of heat-acclimated rats. Sci Rep 3: 1763, 2013.

36. Creagh EM, Sheehan D and Cotter TG: Heat shock proteins-modulators of apoptosis in tumour cells. Leukemia 4: $1161-1173,2000$.

37. Horowitz $M$ and Assadi $\mathrm{H}$ : Heat acclimation-mediated cross-tolerance in cardioprotection: Do HSP70 and HIF-1alpha play a role? Ann N Y Acad Sci 1188: 199-206, 2010.

This work is licensed under a Creative Commons Attribution-NonCommercial-NoDerivatives 4.0 International (CC BY-NC-ND 4.0) License. 